\title{
A experiência do método ${ }^{1}$
}

\author{
Caroline Blanvillain ${ }^{2}$ \\ Tradução: Monique Farhi ${ }^{3}$ e Leon Farhi Neto ${ }^{4}$ \\ E eu tinha sempre um extremo desejo de aprender \\ a distinguir o verdadeiro do falso, para ver com \\ claridade minhas ações e caminhar com \\ segurança nesta vida. (Descartes, 1673, p. 56)
}

Nós escolhemos dar a este artigo o título de A experiência do método, porque o termo 'método' está no coração da filosofia de François Soulages. Pensar a partir da filosofia de Soulages é pensar o método. No livro coletivo Fotografia e inconsciente, que o autor dirigiu há trinta anos, ele atribui três qualidades à filosofia: ela deve ser ao mesmo tempo existencial, crítica e conceitual. (SOULAGES, 1986) ${ }^{5}$ Essas qualidades são os fundamentos do método.

François Soulages, o professor, convida, nos seus seminários, os seus estudantes a pensar com método. O método proposto - 'proposto' deve ser entendido, aqui, no seu sentido primeiro, submetido à reflexão - implica trabalhar o problema: "Colocar um problema significa trabalhar o problema. Não narrar, mas mostrar os problemas." ${ }^{\prime 6}$ Como trabalhar um problema filosófico e/ou estético? Para François Soulages, trata-se de "partir do trabalho do artista. Uma frequentação e uma prática de imagens." "7 Como partir das obras de um artista sem convocar a experiência, e precisamente a experiência estética?

Em sua filosofia, em seu ensino, dois elementos indistinguíveis um do outro, François Soulages faz seu convite a pensar, propondo abordar o objeto da pesquisa segundo diferentes eixos, para depois entrecruzar as diferentes perspectivas. François Soulages não prega no seu método outra coisa senão o que ele desenvolveu na sua estética da fotografia: uma estética do ao mesmo tempo.

\footnotetext{
${ }^{1}$ Título original: L'expérience de la méthode. (N.T.). Tradução recebida em 21/04/2020 e aceita em /07/2020.

${ }^{2}$ Caroline Blanvillain é professora de Estética, na Universidade de Montpellier; associada ao Laboratório AIAC, Universidade Paris 8 - França. (N.T.)

${ }^{3}$ Arte-educadora UDESC, o francês é sua língua materna.E-mail: moniquefarhi@gmail.com.

${ }^{4}$ Filósofo, professor de filosofia da UFT. Pesquisa atualmente as relações entre imagem, memória e poder. E-mail: leon@uft.edu.br.

${ }^{5}$ Conferir a tradução deste texto na Revista Perspectivas (SOULAGES, 1986a). A ideia de ao mesmo tempo (no francês: "à la fois"; mais literalmente: "de uma só vez") pertence à estética da fotografia de Soulages. (N.T.)

${ }^{6}$ Apontamentos da autora, a partir das falas de François Soulages, pronunciadas no $12^{\circ}$ Seminário da INHA, em 19 de março de 2012.

${ }^{7}$ Idem.

Perspectivas - Revista do Programa de Pós-Graduação em Filosofia da UFT - volume 5, n. 1 - 2020
} 
Nós colocamos a hipótese de que a razão pela qual François Soulages dirigiu a sua atenção e o seu pensamento para a imagem, em particular para a imagem fotográfica, é que a articulação desses dois termos, experiência e método, nos precipita na articulação do objeto e do sujeito, e que é próprio à fotografia questionar ao mesmo tempo o objeto e o sujeito. É raro François Soulages evocar de modo explícito, nos seus escritos, a experiência; no entanto, ela nos parece onipresente. Nós vamos tentar demonstrá-lo.

A priori, o método se opõe à experiência: por quê? Porque o método é a maneira de conduzir e de expressar o seu pensamento conforme os princípios do saber, mais especificamente, é um procedimento racional destinado a descobrir e demonstrar a verdade. Ora, a experiência, quanto a ela, é o fato de adquirir, ou desenvolver, voluntariamente ou não, o conhecimento dos seres e das coisas, por meio de uma prática e de uma confrontação, mais ou menos longas, de si com o mundo. Mais especificamente ainda, a experiência é o conhecimento adquirido, seja pelos sentidos, seja pela inteligência, seja por ambos; ela se opõe ao conhecimento inato implicado pela natureza do espírito. Como articular um e outro, sem perder um ou outro? Veremos que a experiência e o método, longe de se oporem um ao outro, estão estreitamente entrelaçados.

\section{Método vs metodologia}

Antes de mais nada, interrogar a experiência do método convoca Descartes e o seu Discurso do método. O filósofo engajou-se em conceber um método que explicitasse o conjunto de princípios requeridos para bem conduzir a sua razão, e para buscar a verdade nas ciências. O seu método se apoia em quatro preceitos: a dúvida, a divisão, a ordem e a enumeração. O que nos interessa aqui não é tomar posse desses preceitos, e aplicá-los; pois, com isso, o método se tornaria metodologia. Ora, a metodologia não nos parece operante para empreender uma pesquisa. Não operante, porque ela é anterior ao pensamento, porque ela se aplica logicamente a todo objeto, porque ela é dogmática. A metodologia é distinta do método, no sentido de que a metodologia é uma abordagem lógica e preordenada, e o método, uma conduta do pensamento e um pensamento em ato.

No Discurso do método, nota-se que Descartes nos oferece seu procedimento, sua experiência, e isso, de maneira muito precisa; além disso, a sua biografia esclarece as condições dessa sua experiência. Com efeito, em primeiro lugar, o filósofo cria para si as condições do

Perspectivas - Revista do Programa de Pós-Graduação em Filosofia da UFT - volume 5, n. 1 - 2020 
filosofar ${ }^{8}$ : ele se isola, durante várias semanas de inverno, num povoado da Alemanha; em segundo lugar, ele nos oferece o caminho do seu pensamento. Descartes escreve: "Depois de eu ter passado, alguns anos, a estudar o livro do mundo e a me empenhar em adquirir alguma experiência, um dia, resolvi estudar, também, a mim mesmo.” (DESCARTES, 1637, p. 57) O que preocupa Descartes é um método que lhe permita utilizar o todo de sua razão, um método que lhe torne acessíveis todos os conhecimentos, a fim de que ele possa possuir verdadeiros bens; é isso que, avalia, o tornará feliz e lhe permitirá conduzir a sua vida no exercício da sabedoria. Em Descartes, o problema da conduta da vida se confunde com o problema da conduta do pensamento; isso é um ponto importante. Podemos constatar, nesse texto, que a preocupação de Descartes se dirige, em primeiro lugar, para o sujeito, mesmo que ele proponha um método científico fundamentado nas matemáticas; o que lhe importa é "caminhar com segurança nessa vida.” (DESCARTES, 1637, p. 56). O ponto de partida pelas matemáticas é escolhido, porque elas aparecem, para o autor, como o objeto mais claro e preciso a se pensar, como o primeiro passo para empreender uma descoberta da verdade.

De nossa parte, o que nos parece crucial, no procedimento de Descartes, é sobretudo a razão por que ele escreveu seu Discurso do método, e não o resultado desse procedimento, ou seja, o desvelamento de uma metodologia organizada em preceitos. O método aparece nisso: Descartes ordena o seu pensamento para chegar à sabedoria. Descartes faz um clara distinção entre o fato de buscar desenvolver a erudição do sujeito e o fato de aumentar a sabedoria do sujeito; na introdução, ele escreve: "As maiores almas são capazes dos maiores vícios, assim como das maiores virtudes; e aqueles que não caminham, senão muito lentamente, se eles seguem sempre o reto caminho, podem avançar muito mais do que aqueles que correm ou que dele se afastam.” (DESCARTES, 1637, p. 44) ${ }^{9}$ O filósofo aspira à sabedoria, e busca um método para adquiri-la. A sabedoria reside na conduta do pensamento, no espírito do pensador; ela se volta para o sujeito, enquanto a erudição se volta para o objeto.

O romance de ficção científica de Daniel Keyes, publicado em 1966, Flores para Algernon $^{10}$, ilustra bem essa distância entre sabedoria e erudição. Nesse livro, o personagem principal, Charlie, é o gentil idiota que é operado para se tornar inteligente; seguimos então o percurso de um ser idiota, e depois inteligente, com tudo o que isso implica como

\footnotetext{
${ }^{8}$ François Soulages, por sua vez, nos chama a atenção para essas condições materiais. (SOULAGES, 1986a)

${ }^{9} \mathrm{O}$ texto de Descartes fala claramente do aspecto moral.

${ }^{10}$ Fomos informados, depois de escrever essas linhas, que François Soulages foi marcado pela leitura dessa obra, nos anos 70.
}

Perspectivas - Revista do Programa de Pós-Graduação em Filosofia da UFT - volume 5, n. 1 - 2020 
posicionamento na sociedade. Vemos o personagem se debater com inúmeras imagens: a sua imagem, a imagem que os outros têm dele, aquela que eles lhe devolvem conforme o seu nível de inteligência. O herói, Charlie, descobre coisas que ele não pensava que existissem. Ele se dá conta de que os conhecimentos são infinitos, e que conduzir a sua razão para adquirir sempre novos conhecimentos é uma meta sem fim. Mais ainda, ele nota que a erudição trabalha, ou constrói, a imagem dos eruditos que ele frequenta, nada mais que a imagem. Ele lamenta, com efeito, a maneira com a qual o famoso cirurgião que o operou o considera: "Se somente Nemur fizesse a gentileza de me considerar como um ser humano." (KEYES, 1960, p.157) Charlie se dá conta de que é apenas mais um objeto de estudo, para esse homem de ciência, mas desumanizado. É o início da sua desilusão, o início da sua infelicidade. A sua busca de conhecimentos chega a termo, então, para dar lugar e sentido à verdade, à verdadeira sabedoria. E o herói só encontra a sua salvação, quando se torna novamente um idiota.

Toda a questão da distância entre o objeto e o sujeito está contida na questão da visada ${ }^{11}$. François Soulages visa fazer filosofia, não ter em mãos uma pronta par uso. E é por isso que ele está mais preocupado com o sujeito do que com o objeto. No livro, O homem desaparecido, Fotografia e corpos políticos, que ele codirigiu com Silvia Solas, Soulages escreve: "E o que importa não é tanto os objetos, mas as relações; aliás, um sujeito é mais uma relação do que um objeto, é mais um projeto do que uma coisa, é mais uma articulação do que algo fixo: um sujeito é um potencial de inteligências, consequentemente, de relações. Relações para experimentar pensar, por exemplo, em e por imagens fotográficas." (SOULAGES, SOLAS, 2016, p. 7)

Uma das qualidades da filosofia encontrada por François Soulages, o critério existencial, convoca claramente a experiência. Qual é o objetivo da elaboração de um método relacionado com a experiência? O método não se elabora de uma vez por todas, nem para Descartes, nem para Soulages. Descartes escreve: “Assim, meu desígnio, aqui, não é ensinar o método que cada um deve seguir para bem conduzir a sua razão, mas somente expor a maneira com que eu tentei conduzir a minha." (DESCARTES, 1637, p. 48) O método se elabora no decorrer do pensamento, em função das condições, dos encontros; é a razão pela qual ele não pode ser senão experiência, experiência do espírito, do corpo, do sujeito. Ele envolve a vida do sujeito. Descartes não procede de maneira diferente quando ele nos fornece seu Discurso do método. Ele enuncia claramente qual foi seu trajeto, seu encaminhamento: "Mas me agradaria

\footnotetext{
${ }^{11}$ No francês, la visée: a visada, o ter algo em vista, o ter algo em mente. (N.T.) Perspectivas - Revista do Programa de Pós-Graduação em Filosofia da UFT - volume 5, n. 1 - 2020
} 
muito expor, neste discurso, quais são os caminhos que eu segui, e de aí representar minha vida, como em um quadro." (DESCARTES, 1637, p. 47)

O pensamento pode ser um objeto a se pensar, um objeto de pensamentos; mas o objeto pensado não é independente do sujeito pensante, não há um sem o outro. Imaginar que o objeto pensado seja isolado não concorda com a razão; paradoxalmente, surge uma espécie de confusão entre o objeto e o sujeito, quando pensamos que são estritamente independentes. E o método se aplica em desenvolver o pensamento e, consequentemente, o sujeito. E o sujeito não pode se desenvolver senão com a experiência, o vivido, pois um pensamento só se desdobra a partir de um sujeito.

Por que a fotografia vem a ser um objeto privilegiado a se pensar? Ora, porque a fotografia é o objeto que, por excelência, convoca o sujeito. Mais ainda, a fotografia é um lugar, um espaço de confusão entre o objeto e o sujeito. Isso se deve tanto ao próprio processo da fotografia, como ao seu espaço de recepção.

\section{O caminhante, ser-aí}

Chegou a hora de interrogar a própria imagem fotográfica, e existe um trabalho paradigmático sobre essa questão: a obra do artista Richard Long, inglês, nascido em 1945 em Bristol. Sua obra é densa e rica; partamos da sua obra emblemática, A line made by Walking, England, 1967. (LONG, 2016) O meio que nos dá acesso a essa obra é uma fotografia legendada, em preto e branco. A imagem mostra uma linha reta mais clara que o resto, visivelmente realizada após um pisoteio repetido no meio de um campo florido; ao fundo, uma parede de árvores mais escura. Essa imagem fotográfica foi tomada numa área rural inglesa; a linha branca é o resultado das idas e vindas do artista. O trabalho artístico de Richard Long está presente nessa obra: o artista faz, literalmente, a experiência do terreno, ele caminha, e a obra nasce desse caminhar. A obra de Long, em particular o corpus que escolhemos, é oportuna para pensar a partir da filosofia de François Soulages, e isso por várias razões.

\section{Correspondências}

A primeira razão é que o artista, como François Soulages, é um caminhante. Para Richard Long, a caminhada a pé é indissociável da produção da obra. O trabalho é um trabalho do corpo no espaço, esse tempo de construção é um tempo vivido. A primeira fotografia de

Perspectivas - Revista do Programa de Pós-Graduação em Filosofia da UFT - volume 5, n. 1 - 2020 
Long, de 1967, é o resultado de um longo caminhar repetitivo. O corpo está no centro dessa obra. François Soulages pensa enquanto caminha; passo a passo ele interroga, ele pensa para si mesmo e para a filosofia. (SOULAGES, 1986a) Existem correspondências entre a filosofia do caminhante François Soulages, a fotografia que ele estuda e a experiência do método que nós desenvolvemos neste texto. Escolhemos trabalhar a experiência do método, trabalhando a imagem fotográfica A line made by Walking, England, 1967.

Richard Long, em sua ação sobre a paisagem, nos mostra que ele não tinha, previamente, a intenção precisa de fazer uma obra. Certamente, ele faz projetos de caminhadas; mas, enquanto o artista não é lançado na paisagem, nada está feito. Na sua obra, Long parece nos indicar que não há objeto prévio, preconcebido, que poderia ser investigado numa visada teórica. Ela incarna a diferença entre metodologia e método.

Assim como a execução da obra de Long na paisagem, o método de pesquisa por experiência gasta muita energia. Por quê? Porque ele é repetitivo, infinito e aberto a todos os possíveis. O que deve ser admitido não é, de todo algum, repouso. Seria mais fácil ter um espaço definido, uma metodologia sedimentada. Mas, se as coisas fossem fixas, se nós possuíssemos certezas, coisas, objetos, um canto de território, se simplesmente nós os possuíssemos, então, de fato, estaríamos menos cansados, mas deveríamos encarar a perda e o resto.

Por que François Soulages escolhe filosofar a partir da fotografia? Porque a fotografia diz exatamente isso: a perda e o resto. Ela é o estigma; é, ao mesmo tempo, marca e marcação ${ }^{12}$ (SOULAGES, 1986a) - e isso se expõe claramente na obra de Richard Long.

O movimento que anima Richard Long é respiração, plasticidade e, igualmente, rigor e repetição. Ora, o termo 'método' também pode se definir como a maneira de fazer alguma coisa conforme um certo hábito, segundo uma certa concepção ou com uma certa aplicação. Estamos diante de uma experiência metódica, que implica o pôr-se em movimento de um corpo. A caminhada implica uma lentidão necessária, um objetivo longínquo, mesmo que pouco definido, um trajeto um pouco incerto, talvez, mas sempre animado por uma visada. Para caminhar, é preciso não olhar para os seus pés, não estar demasiado próximo a si mesmo; convém não levar seu olhar para muito longe, para estar bem em contato com o chão; mas convém, também, manter a visada distante, para atravessar as montanhas. A caminhada é um pensamento em movimento, um pensamento encarnado, um pensamento aqui, um ser-aí. A

\footnotetext{
${ }^{12}$ No francês: trace et tracé. Trace: traço no sentido de vestígio, rasto, marca de uma passagem. Tracé: traço traçado, efeito do ato de traçar. (N.T)
}

Perspectivas - Revista do Programa de Pós-Graduação em Filosofia da UFT - volume 5, n. 1 - 2020 
caminhada é um equilíbrio a meio-caminho entre si mesmo, aqui e agora, e si mesmo, alguns passos e instantes mais tarde. Assim, podemos definir o fato de caminhar como aquele de se posicionar, de tomar posição, mantendo-se aberto, no entanto, à multiplicidade do mundo, porque caminhar é sempre se aproximar de si mesmo.

Encontramos essas mesmas características na fotografia, porque ela convoca o movimento. Contra isso que, em geral, se crê, com certeza; pois alguém poderia nos obstar que a imagem fotográfica é, por essência, estática, que ela capta um instante, e o traduz com aqueles famosos "instantâneos"; de fato, porém, não é nada disso; a fotografia, a imagem fotográfica, precisamente, é espaço traduzindo o tempo, não tanto um tempo passado como um tempo por vir, sem negligenciar o tempo presente.

\section{Pôr em obra ${ }^{13}$}

A segunda razão pela qual nos apoiamos em Richard Long se deve ao fato de que as fotografias dos resultados da caminhada, fotografias que podem ser expostas num museu, são imagens, elas não são as obras; o que faz obra, nos trabalhos de Long, é a própria experiência vivida. A obra não é somente o resultado da caminhada, mas a própria caminhada, nenhuma distinção aqui é possível. A caminhada cria a obra e faz obra. Assim, a foto nos ilude, ela não é um objeto-obra, só a ação é obra, e devemos reconhecer que se trata aqui mais do sujeito que do objeto. As fotos de Long não são uma representação de uma paisagem esculpida pelo artista, elas são uma memória, uma prova da experiência do artista como caminhante e criador. Quando olhamos o trabalho de Long, não nos confrontamos com o objeto-foto, com o objeto-paisagem, mas com o sujeito Long.

As fotos são apenas imagens; o que faz obra é o tempo passado a criar uma paisagem num espaço particular. Ora, encontramo-nos no cerne da experiência do método: não é o objeto que preocupa, é o sujeito. Essa imagem fotográfica nos mostra um ser-aí, agora. Da mesma maneira, porque a fotografia questiona a realidade, o ser humano e o mundo, não é a fotografia o objeto de pesquisa; como em Long, não é a foto que faz obra. As fotos de Long não são suas obras; o que faz obra em Long é o tempo passado num espaço particular a criar uma paisagem. Da mesma maneira, para François Soulages, não é o objeto que preocupa, mas o sujeito a criar.

\footnotetext{
${ }^{13}$ No francês: mise en cuvre. (N.T) Perspectivas - Revista do Programa de Pós-Graduação em Filosofia da UFT - volume 5, n. 1 - 2020
} 
Certamente, a foto dá conta de um isso foi e de um isso foi encenado, mas é essa última expressão que nos precipita na experiência: isso foi vivido ${ }^{14}$. Com efeito, na expressão isso foi encenado existe um movimento presente. Esse movimento, no caso das fotos de Long, é a obra; a fotografia não é a obra, mas a marca da obra, quer dizer, o movimento do artista criando. Notemos que, no caso de Long, os termos fazer obra e ser uma obra se aproximam. Essa foto nos mostra, portanto, um ser-aí, no sentido do Dasein heidegeriano. Pois o que importa para Long é ser-aí num espaço, é o aqui e o agora. Enquanto a fotografia nos mostra o lá e o antes. Isso explica por que a fotografia nos incomoda tanto, e por que é tão preciso trabalhá-la. Ela expõe o ser-aí do sujeito, seja ele artista ou pensador.

\section{Experimentar}

A terceira razão pela qual essa obra, A line made by Walking, England, 1967, é uma obra exemplar, é que ela é uma imagem fotográfica e, sendo isso, convoca a experiência do sujeito-que-olha. A imagem é objeto e trabalha o sujeito. Mais ainda, ela coloca em questão o sujeito-que-olha, pois o próprio espaço da recepção não é estável. A imagem fotográfica é objeto privilegiado para o sujeito que trabalha o sujeito. Pois ele precipita o sujeito no abismo. A expressão é um pouco forte; mas uma foto não nos leva a espaços distintos, a tempos sobrepostos? Isso é realmente vertiginoso.

A indistinção entre objeto e sujeito, em fotografia, se deve certamente à relação com a realidade, mas também à experiência estética. As imagens trabalham o sujeito-que-olha sem que ele saiba. Quem olha faz a experiência do encontro com a imagem fotográfica e essa experiência é método para pensar. O método se constrói no decorrer do tempo; ele é, como a experiência, próprio ao objeto de pesquisa, ao sujeito-pesquisador, próprio ao objeto mesmo que é o pensamento. Na experiência, o sujeito está em movimento; a imagem fotográfica faz imagem em seu espírito, e este se anima: ligação, deslocamento, sombra. A experiência segue o caminho da psique e seu método: ligar e religar, sem parar, mas de modo desordenado, sem por isso ser aleatório. O sujeito não se confunde com o objeto, mas ele está em relação constante com ele, mudando sem parar.

Certamente, com Descartes, é preciso ordenar o pensamento, mas nós estimamos que é impossível constringi-lo a montante. Ele precisa primeiro de espaço e de tempo. E essa é uma

\footnotetext{
14 'Isso foi' (no francês: 'ça a été', isso aconteceu) exprime a atitude e a ideia de Roland Barthes acerca da fotografia. 'Isso foi encenado' (no francês: 'ça a été joué') exprime a atitude e a ideia críticas pertinentes à estética da fotografia de François Soulages. (N.T.)
}

Perspectivas - Revista do Programa de Pós-Graduação em Filosofia da UFT - volume 5, n. 1 - 2020 
das razões pela qual a fotografia é um objeto formidável para o sujeito que quer pensar ou filosofar. Pois a fotografia é espaço e tempo, mesmo se, por causa do seu processo, ela cria uma zona embaçada em torno dessas duas noções. A imagem fotográfica é espaço e tempo oferecidos à experiência do sujeito.

\section{Do objeto ao sujeito}

Dissemos que a fotografia é o objeto paradigmático para se colocar a questão da articulação do objeto e do sujeito, pois, apesar de todas as evidências, ela se aplica primeiro ao sujeito e, depois, eventualmente, ao objeto. A fotografia tem uma questão a resolver com o sujeito, com a psicanálise e, particularmente, com a ficção freudiana do aparelho psíquico.

François Soulages interrogou o aparelho psíquico freudiano em ligação com a fotografia. Mas, ao que nos parece, o paradigma enunciado por Soulages em seu livro Estética da fotografia, o isso foi encenado, não foi plenamente explorado. Com efeito, desse paradigma, em geral, retém-se só a dimensão teatral, ou seja, o "...foi encenado"; o "isso" não parece ter sido entendido, apesar de Soulages enunciar claramente a dimensão psicanalítica desse "isso"15. (SOULAGES, 1998, p. 63-64)

Se a fotografia é, com frequência, comparada à ficção estabelecida por Freud a respeito do aparelho psíquico, é porque as instâncias descritas por Freud são identificadas como lugares. A fotografia convoca o lugar, o espaço e também o tempo. Freud abordou, numa segunda tópica, as relações dinâmicas que ligam três instâncias psíquicas: o isso, o eu e o supereu ${ }^{16}$. Para explicar o conjunto dos processos mentais, o psiquiatra acrescentará ainda o Ideal do $\mathrm{Eu}$, modelo de referência, muito investido narcisicamente, que o individuo espera igualar.

A fotografia, devido à maneira com que o aparelho psíquico a ecoa, coloca o sujeito em movimento. E esse movimento é uma instabilidade. Ora, a razão se sentiria reconfortada ao frear esse movimento. Mas isso seria ignorar que o movimento é justamente a instância do equilíbrio e da estabilidade, basta observar mover-se um dançarino.

François Soulages escreve: "Pensar a imagem é pensar a articulação entre a imagem material e a imagem psíquica. Não há imagem material sem imagem psíquica, e não há imagem psíquica sem imaginação de imagem material. Esse é o problema colocado por toda a

\footnotetext{
${ }^{15}$ No francês: "ça" traduz o termo alemão " $E s$ ". Nos textos de psicanálise em português, usa-se, em geral, o termo em latim, "Id", ao invés de "isso". (N.T.)

${ }^{16} \mathrm{Ou}$, respectivamente, "Id", "ego", "superego". (N.T.)

Perspectivas - Revista do Programa de Pós-Graduação em Filosofia da UFT - volume 5, n. 1 - 2020
} 
problemática sobre a fotografia." 17 Com efeito, há também um elemento crucial com a fotografia: trata-se do fato de que, diante de cada imagem, o estágio do espelho é reencenado; assim, toda imagem participa da construção do sujeito. Que a imagem fotográfica represente tal ou tal paisagem (ou um retrato, uma natureza morta, qualquer que seja o objeto fotografado), a experiência diante da imagem é sempre real, e pode ser integrada à nossa vida psíquica.

Por um lado, é certo, dar-se o tempo de olhar não significa que haverá experiência estética. Por outro, porém, a recepção da imagem projetada terá um impacto sobre quem olha (qualquer que seja esse impacto); a possibilidade de levar em conta ou não a sensação vivida pertence à consciência, mas o inconsciente a espreita. É por isso que a experiência não é uma iluminação, ela é construção, deslocamento, movimento. Ela está a caminho e requer tempo. Mas isso implica um momento de desfocamento e de desestabilização, um abalo da razão. Assim, o isso foi encenado de Soulages deve ser entendido como o "isso" foi encenado ou o "isso" foi enganado.

\section{Retorno ao método}

E qual será, então, a meta desse olhar para a imagem, se não há uma visada prévia? Aquela de levantar questões. Mas ninguém, entre nós, vai levantar as mesmas questões. A pesquisa é dependente tanto das condições de pesquisa quanto do sujeito. A fotografia salienta a incontornável subjetividade do método, porque ele está ligado ao objeto de pesquisa, que é ligado ao sujeito. Mas, também, porque a imagem, a imagem fotográfica, é impossível dividila com clareza e distinção. Ela é um todo ao qual devemos nos ater, ela não é matematicamente redutível. Querer cindir o objeto é querer dissociar, é, de fato, jogar o jogo do objeto; pois é ele, é o objeto, a imagem mesma, que de fato cinde o sujeito. O método não consiste, portanto, em cindir o objeto, mas em interrogá-lo por toda parte, em todos os sentidos, e finalmente associar, ecoando os movimentos do aparelho psíquico.

Daí a riqueza de pensar com imagens, por imagens, pois elas participam da construção do sujeito; talvez até, simplesmente, radicalmente, nós poderíamos avançar que as imagens, todas as imagens, quaisquer que sejam, nos constroem. Sobre isso, Soulages escreve em $O$ homem desaparecido: "E isso nos diz respeito a todos. Não tanto porque a política nos tece e nos habita, mas porque as imagens e as fotos em particular, hoje em dia, nos assombram e nos

\footnotetext{
${ }^{17}$ Notas da autora a partir das falas de François Soulages, no $12^{\circ}$ seminário da INHA, em 19 de março de 2012. Perspectivas - Revista do Programa de Pós-Graduação em Filosofia da UFT - volume 5, n. 1 - 2020
} 
nutrem, conscientemente ou não, e de maneira trágica e inesgotável: não se pode encerrar os efeitos de uma foto sobre um sujeito." (SOULAGES, 2016, p. 9)

Mas trata-se, ainda aqui, de uma questão de método? Sim, é uma questão de método, quando nos atemos a encontrar os fundamentos, os lugares, as imagens do pensamento. A imagem é o terreno, o lugar do pensar, em eco com o aparelho psíquico. No cerne do sujeito, as imagens estão para olhar ou para esquecer, não importa: o inconsciente faz seu trabalho quando o consciente se esquiva. E esse terreno, esse húmus, esse lugar do pensar é experiência. François Soulages nos incita a acolher as contradições e as desordens, a abrir as concordâncias. E não pode ser de outro modo, porque o nosso inconsciente trabalha, apesar de nós. Abrir as concordâncias necessita recorrer à experiência.

No seu método, Descartes divide em pedaços os objetos e procura a ordem, ele se preocupa, em primeiro lugar, em interrogar as matemáticas. Pois é preciso, para pensar, que esses objetos sejam bem legíveis, visíveis, acessíveis, e depois organizados, arrumados - eu ousaria dizer -, para uma experiência científica. A introdução do aparelho psíquico de Freud implica, no entanto, zonas de sombra, objetos desfocados, frequentemente inacessíveis; e, mesmo assim, essas zonas de sombra são constitutivas do sujeito, inegáveis, mas inefáveis. Aliás, é particularmente notável que Descartes, com seu rigor demonstrativo, sua exigência de objetividade, chegou ao cogito, ao sujeito mesmo.

A imagem permite pensar de outra maneira, sempre metodicamente, mas de maneira diferente. Com Descartes, o método ${ }^{18}$ implica partes distintas e claras; ora, a fotografia ecoa o nosso inconsciente; o que há de mais confuso e obscuro? Não se trata de aplicar à imagem uma metodologia predefinida, pois nós vemos que a imagem desafia o sujeito-que-olha. Ele não pode desconsiderá-la; então, o método tem que ser plástico, deslizante, intuitivo, quase impalpável. A experiência do método, a pesquisa, é uma configuração movediça, na qual se caminha, e que ganha sentido com esse caminhar.

\section{A subjetividade da experiência}

\footnotetext{
${ }^{18}$ Notemos que os homens são propensos a reter os pensamentos como que congelados, ou a tratar as afirmações dos filósofos como se fossem estátuas. De fato, Descartes afirma propor, em seu escrito, "uma história" ou ainda "uma fábula" (DESCARTES, 1637, p. 48); e, por sua vez, Freud propôs uma "ficção" do aparelho psíquico.

Perspectivas - Revista do Programa de Pós-Graduação em Filosofia da UFT - volume 5, n. 1 - 2020
} 
Nós convocamos neste texto a experiência; mas o que entendemos por esse termo? Soulages qualificou a filosofia de existencial. O termo existencial implica que a filosofia "tem a ver, de perto ou de longe, com os problemas da existência concreta." (SOULAGES, 1986a) Isso implica, é óbvio, a experiência vivida. A advertência de François Soulages, no entanto, esclarece: "[a vida cotidiana] é da ordem da experiência; [...] mas, se o ponto de partida ou de chegada pode ser vivido, singular, cotidiano e imediato, $[. .$.$] a filosofia não fica nunca nesse$ nível: é somente por mediações sucessivas que ela se relaciona com esse imediato." (SOULAGES, 1986a) O que é dito, aqui, de modo claro, é o afastamento da Erlebnis em proveito da Erfahrung. ${ }^{19}$ Quer dizer, nós entendemos a palavra experiência sem alcance subjetivista, sem vivido subjetivista (no sentido em que é concebida com o termo Erlebnis). É preciso, então, bem especificá-la como Erfahrung, experiência entendida como relação interativa com o mundo, ou seja, um método de investigação por entrecruzamentos, pelo $a o$ mesmo tempo. ${ }^{20}$ Essa relação, implicada pela Erfahrung, com suas remissões ao mundo, também não deve ser reduzida a um sentimento, a algo sentido. A experiência que convocamos ultrapassa a experiência como Erlebnis, para alcançar a Erfahrung.

Por sua vez, em A experiência estética, Jean-Marie Schaeffer escreve: "não existe processo emocional desprovido de dimensão cognitiva [...], cada emoção é o produto direto ou indireto [...] de uma avaliação cognitiva, mesmo se ela não é sempre consciente e nem sempre confiável.” (SCHAEFFER, 2015, p. 141) Da sua análise, sobressai que a emoção e a cognição são dois sistemas intimamente ligados.

E nós reencontramos, nisso, o fato de que a imagem, como a filosofia, desloca o sujeito, e de que a experiência e o método são intimamente interligados. A pesquisa em estética e em filosofia é polifônica. A experiência permite desdobrar uma atenção aberta, sem tarefas designadas de antemão. É uma atitude que é invasora, pois sem limite, porque nenhuma programação é estabelecida na origem. Essa pesquisa necessita, então, desdobrar-se no tempo, ela é consumidora de muita energia vital. Mais ainda, a experiência pelos abismos ${ }^{21}$ implica mergulhar no cerne do sujeito, ultrapassar os limites do consciente, para solicitar o inconsciente.

\footnotetext{
${ }^{19}$ Em alemão no original. (N.T.)

${ }^{20}$ Essa ideia de ao mesmo tempo, nós a encontramos também na dimensão crítica da filosofia, mas sob uma variante que toma a forma do "nem... nem..." (SOULAGES, 1986a)

${ }^{21}$ Conferir a troca de cartas (1921-1925) entre Ludwig Biswanger e Aby Warburg. (WARBURG, BISWANGER, 1921-1925)

Perspectivas - Revista do Programa de Pós-Graduação em Filosofia da UFT - volume 5, n. 1 - 2020
} 
Desse modo, a subjetividade não é entendida como condição para uma experiência sensível isolada e algo sentimentalista, mas como um método para pensar. A subjetividade deve estar presente, porque o pesquisador é um sujeito-pesquisador. Ele não pode ignorar o que ele é, ele não pode pensar ex-nihilo. A fotografia interroga o sujeito em todas as suas dimensões psíquicas; nela ecoam tanto o consciente como o inconsciente. Apesar de todos os nossos esforços em nos ater a considerar as fotos estudadas em função dos seus próprios contextos, é o nosso contexto que retorna.

A subjetividade da experiência, então, deve ser considerada. Os pensamentos que se desdobram na experiência do ser-aí, aí e agora, diante da imagem, dentro da paisagem, nascem de um encontro entre o objeto e o sujeito. O sujeito é mestre do seu método, porque este se funda na experiência. Uma metodologia ordenada e preditiva não é capaz de enfrentar um sujeito em movimento e em desenvolvimento.

Portanto, a experiência não tem uma visada subjetivista e sentimental; ainda mais, para retomar Schaeffer, a experiência e, em particular, a experiência estética, "é o conjunto dos processos interacionais de natureza cognitiva, emotiva e volitiva que constituem nossa relação com o mundo e com nós mesmos, assim como o conjunto das competências adquiridas pela recorrência desses processos." (SCHAEFFER, 2015, p. 38) Mas o termo competência não significa conhecimento.

\section{Objetivamente o sujeito}

Nós propomos que aquilo que nomeamos a experiência do método implica trazer à luz conceitos claros e distintos, objetos de conhecimento, e isso por várias razões. Primeiro, para que o sujeito possa se inscrever no mundo, porque só o conceito é comunicável. Depois, porque só o conceito honra o outro, o outro sujeito. E, ainda, porque o conceito fala do mundo e não de si mesmo (mesmo se a fonte, na origem do conceito, é o si). Só o conceito respeita o sujeito, todos os sujeitos: o próprio si, porque ele evita o exibicionismo; o outro, porque o conceito é uma pedra no edifício do mundo. Sendo assim, trabalhemos uma outra imagem fotográfica escolhida na obra de Richard Long; uma outra imagem paradigmática. A obra de Long é novamente uma obra recurso, uma obra fonte. Sua obra se situa, tanto a montante quanto a jusante, no processo de pensar e de buscar. 
Essa segunda fotografia é Gobi desert circle, Mongolia, 1975. (LONG, 2016) A fotografia, em preto e branco, mostra uma extensão desértica com um círculo formado por pedras. O motivo do círculo é retomado por Long várias vezes, ao longo dos anos: Silence Circle Big Bend Texas, 1990, essa imagem mostra mais um disco que um círculo, como se o solo tivesse sido varrido dessas pedras, distinguimos a terra como que desnudada; uma outra foto declina o motivo círculo: A Circle in Antarctica, 2012, dessa vez são pedaços de gelo, que desenham em linha pontilhada um círculo num terreno pedregoso cercado de neve. A experiência do método poderia se aparentar a essas organizações, a essas entradas múltiplas, ela poderia inscrever-se nessa produção de relações dos elementos uns com os outros. A necessidade de construir conceitos inscreve-se no fato de que, assim objetivados, eles podem, por sua vez, ser deslocados, recompostos, destruídos, enfim, trabalhados. A experiência do método implica tornar possível a mobilidade: uma pedra, um conceito que podemos deslocar para construir, com uns, esculturas, com outros, pensamentos. O conceito é essa pedra que pode ser pesada e densa, mas que permanece móvel e autônoma. Conceituar é adicionar pedras. Com essas pedras, como Long, criamos uma nova paisagem.

\section{O tempo da experiência}

Para fundar um conhecimento, é preciso declinar motivos, entrecruzar abordagens. Diante da pesquisa, diante do tempo, diante da imagem, todos os tempos interferem uns com os outros; é preciso criar, com todos esses anacronismos e mecanismos psíquicos, uma nova objetividade. De novo, convoca-se a estética do ao mesmo tempo de François Soulages. Mas questionar o objeto de pesquisa por todos os lados não é suficiente, é preciso, ainda ou simultaneamente, fazer a experiência das imagens, no sentido de empreender a prova da imagem fotográfica. Filosofar implica, como o artístico, o fazer, e então, de fato, a experiência.

Porque a experiência estética toca o inefável, ela não deixa de se ligar com o vazio. A imagem fotográfica, enquanto experiência, permite tocar, questionar, o inefável, o vazio. Segundo a hipótese de Jean-Marie Schaeffer, em L'expérience esthétique: "a criação artística e a experiência estética são duas outras tentativas para controlar uma situação de conhecimento incompleta." (SCHAEFFER, 2015, p. 309) Buscar viver experiências estéticas permite deixar na sombra os vazios, questões ou inquietações que habitam o ser humano.

A experiência preenche a necessidade de apreender o "inapreensível", de compensar a falta, o desconhecido, o espaço, o tempo. A criação artística é o fazer que coloca à distância situações de conhecimento incompletas, a experiência estética é o que preenche essas situações;

Perspectivas - Revista do Programa de Pós-Graduação em Filosofia da UFT - volume 5, n. 1 - 2020 
a experiência do método em filosofia é o que nos leva a reduzir esses espaços de conhecimentos incompletos, turvos, e, além disso, é o que permite criar novos conceitos. Se seguimos esse raciocínio, podemos imaginar que, em algum momento, essas situações de vazio de conhecimento não existirão mais para o sujeito? Isso é realmente concebível? Não. Há um elemento nessa questão que é a fonte da sua resposta: o termo "momento". Essa palavra introduz uma dimensão crucial, crucial porque vital, aquela do tempo. Uma dimensão crucial, não porque não dispomos do tempo suficiente para preencher esses vazios (ainda que...), mas sobretudo porque o tempo é o summum do vazio. É por isso que a fotografia é, ela mesma, crucial. Ela é tempo disposto em espaço.

\section{Compreender}

A experiência é um pensamento em marcha, à primeira vista, vertiginosa porque não controlada. Por isso mesmo, a conceituação é uma etapa fundamental. Somente ao fundar-se na razão, uma experiência do método leva em conta o aparelho psíquico, mesmo que isso crie um equilíbrio instável.

Nos gostaríamos de traçar, aqui, um paralelo entre o pensamento de Binswanger e aquele de Soulages $^{22}$. O psiquiatra propõe, em Henrik Ibsen et le problème de l'autoréalisation dans l'art (BINSWANGER, 1949), três elementos necessários para entender o outro: vivenciar, compreender, interpretar ${ }^{23}$. Vemos uma aproximação com as três qualidades da filosofia enunciadas por François Soulages: vivenciar/existencial; compreender/crítica; interpretar/conceitual. A experiência (a vivência) e a interpretação (o conceito) estão interligadas. Como se passa de uma à outra? Com a segunda dimensão, funcionando como articulação entre as duas outras: a compreensão (a crítica).

Com efeito, Binswanger praticava um conhecimento (do sujeito) por intrincamento, um conhecimento implicado (subjetivo), sem dogma. E é aqui que avançamos no compreender. Só que isso é uma posição desconfortável. Pois se trata de um conhecimento por compreensão, isso é por projeção, e isso implica em não temer interpretações abusivas. Do mesmo modo, olhar uma obra, uma imagem, visa uma compreensão da imagem física e da imagem psíquica. É uma compreensão do objeto via sujeito e do sujeito via objeto.

\footnotetext{
${ }^{22}$ Aliás, notamos que François Soulages abriu-se ao pensamento de Binswanger no seu mestrado de filosofia. (SOULAGES, 1975)

${ }^{23}$ No francês: "éprouver, comprendre, interpréter". Encontramos alguma dificuldade com "éprouver": colocar à prova, expor-se à provação, ensaiar, experimentar. Optamos, aqui, por “vivenciar”. (N.T.)

Perspectivas - Revista do Programa de Pós-Graduação em Filosofia da UFT - volume 5, n. 1 - 2020
} 
O que parece essencial para aceder à interpretação, à conceituação, é criar via vivência da compreensão. A experiência possui todos os requisitos para isso. Pois compreender não é acumular informações sobre um objeto, é acessar uma conexão de motivação em que, de repente, o sujeito se abre. É, certamente, um conhecimento singular; porém, compreender é, de fato, o único conhecimento estável possível.

A psique não é tanto uma ferramenta de saber, quanto um objeto de saber; de fato, o único objeto de saber é o sujeito. Mas um saber para quê, para quem? Não percamos de vista o objetivo da filosofia: desenvolver a sabedoria do sujeito e, consequentemente, a sua relação ao mundo, a sua relação ao outro. E a sabedoria não pode advir sem compreensão.

No entanto, alguém poderia nos opor que a dimensão conceitual está truncada, porque não há produção de novos conceitos isolados do sujeito, os famosos objetos claros e distintos. Mas, o conhecimento, o saber em si mesmo, é instável. Toda teoria é, ou será, desmentida; concordamos com Edgar Morin quando ele escreve, em seu livro Enseigner à vivre: "O próprio de uma teoria viva é a biodegradabilidade.” (MORIN, 2014, p. 38) Para os conhecimentos, tudo é questão de escala: alguns serão desmentidos em dez anos, outros em cem, ou até em mil. A compreensão, por sua vez, é atualidade, ela é agora ou ela não é.

Só importa a visada, a razão da empreitada: a busca da sabedoria, a ascensão do sujeito. E essa ascensão passa por uma compreensão do sujeito. Havíamos proposto que a experiência possui todas as qualidades para permitir esse encaminhamento; é isso que também Descartes nos ensina, no seu Discurso do método: ele nos faz parte da sua, das suas experiências, ele diz que, na sua juventude, ele se empenhava "em recolher diversas experiências, em me pôr à prova, a mim mesmo, nos encontros que a fortuna me propunha, e, em todo lugar, em fazer alguma reflexão sobre as coisas que se apresentavam, para que eu pudesse retirar delas algum proveito.” (DESCARTES, 1637, p. 55) Descartes não pode ser considerado, caricaturado, somente como o homem da dúvida e da ordem; essa frase do Discurso do método mostra bem que a experiência e o pôr-se à prova ${ }^{24}$ estão no cerne da sua abordagem.

\section{Delimitar o sujeito para ser-com}

\footnotetext{
${ }^{24}$ No original: "épreuve"; poderíamos ter mantido "vivência". Perspectivas - Revista do Programa de Pós-Graduação em Filosofia da UFT - volume 5, n. 1 - 2020
} 
A filosofia implica um processo de criação similar ao que opera na obra. Pois ela não pode ignorar o inconsciente. Filosofar implica o processo de criação com o desequilíbrio do sujeito que esse processo implica. E se o processo em operação no ato de filosofar é da mesma natureza que o processo em ação nos artistas na criação de uma obra, pensar implica a introdução de um terceiro ${ }^{25}$, fosse ele um objeto, um pretexto.

Em seu escrito De l'œuvre au texte, Roland Barthes distingue uma coisa da outra, a obra do texto; o leitor adota a perspectiva do "texto" e não aquela da obra, a qual pertence toda a seu autor; ele escreve: “[o texto] poderia ser comparado a um sujeito desocupado [...]: esse sujeito bastante vazio passeia [...] no flanco de um vale, no fundo do qual corre um rio; o que ele percebe é múltiplo, irredutível, procedente de substâncias e de planos heterogêneos, desvinculados [...]; todos esses incidentes são apenas parcialmente identificáveis.” E Barthes conclui: "eles provêm de códigos conhecidos, mas a combinação deles é única, funda o passeio como diferença, que só poderá se repetir enquanto diferença.” (BARTHES, 1971, p. 74) JeanMarie Schaeffer, em L'experience esthétique, analisa essa passagem, e considera que a obra aí é abordada "como objeto de experiência antes que como objeto de saber." (SCHAEFFER, 2015, p. 48)

Além disso, a noção de texto em Barthes é comparável ao tempo da experiência da caminhada, mais que ao vagar sem rumo. Esse tempo necessário é, em François Soulages, um tempo sempre em falta. Sempre em falta, pois infinitamente incompressível. E, no entanto, esse tempo deve às vezes se deter, o filósofo deve fazer pausas, e transformar a experiência do sujeito em teoria objetiva, e criar conceitos, fazer obra, e propor ao leitor, ao outro, um texto. E, do mesmo modo, porque ela é um texto no sentido em que Roland Barthes distingue o escrito do texto, a imagem fotográfica permite um ser-com, esse ser-com que é um componente essencial da filosofia de François Soulages: "É preciso reaprender a entender, no sentido de ouvir e ao mesmo tempo no sentido de compreender ${ }^{26}$ [...] Para isso, é preciso saber ser-com: com o texto, com o problema, com a realidade, em suma, com a alteridade. É preciso, portanto, que a razão esteja desperta." (SOULAGES, 1986a)

Não há conhecimento imperecível; por outro lado, há um conhecimento do sujeito, de si, do outro, que fundamentalmente nos distingue do outro e, por isso mesmo, nos descentra, nos torna mais humanos, pois menos centrados em nossas especificidades e no que nos falta.

\footnotetext{
${ }^{25}$ O lugar do terceiro, na criação artística e no fato de filosofar, poderia ser fartamente questionado no processo de criação de Didier Anzieu ou no estágio do espelho de Lacan.

${ }^{26}$ Em francês, "entendre" pode significar "ouvir" ou "compreender". (N.T.)

Perspectivas - Revista do Programa de Pós-Graduação em Filosofia da UFT - volume 5, n. 1 - 2020
} 
Então, aceitar, vivenciar, a experiência, e transformá-la em texto, isso é criar conceitos e, de fato, um novo pretexto a ser utilizado como objeto pelo outro sujeito.

A meta da filosofia é tornar claros os pensamentos e delimitá-los rigorosamente. Ora, parece-nos que a filosofia precisa também delimitar o sujeito, a fim de que ele exerça uma subjetividade razoada. Pois, só então, o sujeito estará apto a encontrar o outro, a ser-com. Isso requer, porém, um movimento contínuo de construção e de destruição, que passa por - tomamos emprestada uma frase de Barthes - "desfazer o $e u$, órgão superior do desconhecimento". (BARTHES, 1977, p. 516)

As fronteiras, que François Soulages tanto trabalha, são antes de tudo os limites, as diferenças entre cada pessoa. Ser-com implica determinar os limites, os seus e os dos outros, discriminar o sujeito do objeto; também não se trata de solipsismo, ou estaríamos sempre sós e no vazio, mas de dom ao outro. Essa fronteira, certamente, não é fixa, ela existe apenas por um momento, sempre incerto. Uma objetivação das experiências é necessária para que o sujeito tenha a medida das suas fronteiras, sempre a redefinir, e assim se torne apto a oferecer um espaço ao outro; então, o ser-com pode advir.

O conceito é pretexto para o sujeito, em sua construção rumo à sabedoria. Portanto, afinal, tanto a fotografia quanto a filosofia questionam o ser humano, e a experiência do método permite ao sujeito ser-aí e ser-com. Essas duas presenças, a si mesmo e ao mundo, permitem ao sujeito advir, numa eterna revolução e ascensão. O que se persegue na experiência do método, não é tanto a produção de novos conhecimentos, mas o alcance da sabedoria. Sabendo - não nos enganemos - que os dois estão intimamente, intrinsecamente, interligados. Filosofar é tomar consciência dos seus próprios contornos e daqueles dos outros. E isso passa por um seraí e agora para um ser-com.

Para encerrar, pedimos emprestado a Levinas a sua fórmula: "Primeiro você, meu senhor."27

\section{Referências bibliográficas}

BARTHES, Roland. (1971) De l'ouvre au texte, in : Le bruissement de la langue. Essais critiques IV. Paris: Seuil, 1971.

\footnotetext{
${ }^{27}$ Em francês: “Après vous, Monsieur.” (N.T.) Perspectivas - Revista do Programa de Pós-Graduação em Filosofia da UFT - volume 5, n. 1 - 2020
} 
(1977) Fragments d'un discours amoureux. In: Euvres incomplètes. Tome III. 1974-

1995. Paris: Le Seuil, 1995.

BINSWANGER. Ludwig. (1949) Henrik Ibsen et le problème de l'autoréalisation dans l'art, trad. M. Dupuis. Bruxelles: De Boeck Université, 1996.

BLANVILLAIN, Caroline. (2017) L'expérience de la méthode. In: SOLAS, Silvia (Org.). Sur la philosophie des images de François Soulages: Altérité - méthode \& arts. Paris: L'Harmattan, 2017. P. 19-43.

DESCARTES, René. (1637) Discours de la méthode. Paris: Vrin, 2005.

DIDI-HUBERMAN, Georges. L'image survivante. Histoire de l'art et temps des fantômes selon Aby Warburg. Paris: Minuit, 2002.

MORIN, Edgar. (2014) Enseigner à vivre. Arles: Actes Sud, 2014.

SCHAEFFER, Jean-Marie. (2015) L'expérience esthétique. Paris: Gallimard, 2015.

SOULAGES, François. (1975) Ego et alter-ego dans la $5^{\circ}$ "Méditation cartésienne" de Husserl. Paris: Université Paris I, Panthéon-Sorbonne, 1975.

(1986) Introduction générale: Philosophie et photographie. In: Photographie et inconscient. Paris: Osiris, 1986.

(1986a) Introdução geral: filosofia e fotografia. Trad. Leon Farhi Neto. Revista

Perspectivas, Palmas, vol. 1, nº 2, 2016, p. 110-129.

(1998) Esthétique de la photographie. Paris : Nathan, 2001.

SOULAGES François; SOLAS, Silvia (dir.). (2016) L'homme disparu: photographie \& corps politiques, 9. Paris: L'Harmattan, coll. Eidos, série RETINA, 2016.

KEYES, Daniel. (1966) Des fleurs pour Algernon. Paris: J'ai lu, 2012.

WARBURG, Aby; BISWANGER, Ludwig. (1921-1925) La guérison infinie. Trad. de M. Renouard e M. Rueff. Paris: Rivages poche, 2011. 


\section{Sítio-web}

LONG, Richard. (2016) <http://www.richardlong.org>, consultado em agosto de 2016. 